\title{
Germinação e propagação in vitro de mogno brasileiro (Swietenia macrophylla King)
}

\author{
Carolina Dias PEREIRA ${ }^{1}$, Cristiani Santos BERNINI ${ }^{1 *}$, Márcia Regina JANTSCH ${ }^{1}$, \\ Reginaldo Antonio MEDEIROS ${ }^{1}$, Luciana Coelho de MOURA ${ }^{1}$
}

${ }^{1}$ Programa de Pós-Graduação em Ciências Florestais e Ambientais, Universidade Federal de Mato Grosso, Cuiabá, MT, Brasil.
*E-mail: cristianibernini@yahoo.com.br
(ORCID: 0000-0003-2470-2210; 0000-0001-6651-4539; 0000-0003-4344-8449; 0000-0001-5222-2914; 0000-0001-8144-3388)

Recebido em 05/04/2021; Aceito em 16/12/2021; Publicado em 28/12/2021.

\begin{abstract}
RESUMO: A intensificação da exploração seletiva de madeiras tem ocasionado grandes perdas na biodiversidade de espécies nativas de alto valor econômico, comprometendo, a sua sobrevivência. O potencial madeireiro do mogno brasileiro é mundialmente reconhecido e, por isso, é também motivo de grande preocupação da comunidade científico. Esta pesquisa objetiva avaliar o efeito de concentrações de reguladores de crescimento na germinação e multiplicação in vitro de mogno brasileiro e analisar aspectos físicos para determinar a eficiência na produção de mudas. Para isso, as sementes foram incubadas em meio de cultura MS no delineamento inteiramente casualisado em esquema fatorial 2 x 4 (duas intensidades de luz e quatro tempos de hipoclorito de sódio), com cinco repetições e quatro sementes por repetição. Aos trinta dias, os explantes isentos de contaminação foram transferidos para tubos de ensaio contendo meio MS e suplementados com diferentes concentrações de BAP e mantidos em sala de crescimento. Para multiplicação os brotos foram transferidos para meio MS e suplementados com diferentes concentrações de BAP e ANA. Obtiveram-se a maior porcentagem de brotações $(83 \%)$ de explantes da porção intermediária de mogno e a utilização de concentrações superiores de ANA e BAP para formação de calos permitindo êxito na produção clonal.
\end{abstract}

Palavras-chave: espécie nativa; plantas lenhosas; micropropagação.

\section{Germination and propagation in vitro of brazilian mahogany (Swietenia macrophylla King)}

\begin{abstract}
The intensification of selective logging causes great losses biodiversity of native species of high economic value, compromising their survival. The wood industry potential of brazilian mahogany is recognized worldwide and, therefore, it is also a cause of great preoccupations of the scientific community. This research aims to evaluate the effect of concentrations of growth regulators on germination and in vitro multiplication of brazilian mahogany and analyze physical aspects to determining the efficiency in the production of seedlings. For this, the seeds were incubated in MS culture medium in a completely randomized design in a factorial scheme 2 × 4 (two light intensities and four sodium hypochlorite times) with five repetitions and four seeds per supplemented with different concentrations of BAP and kept in the repetition. At thirty days, explants free from contamination were transferred to test tubes containing MS medium and supplemented with different BAP concentrations and kept in the growth room. For multiplication the shoots were transferred to MS medium and supplemented with different concentrations of BAP and ANA. The highest number of percentage of shoots $(83 \%)$ in the use of explants of the intermediate mahogany and the higher concentrations of ANA and BAP for callus formation enabling success in clonal production.
\end{abstract}

Keywords: native species; woody plants; micropropagation.

\section{INTRODUÇÃO}

O setor florestal brasileiro passou a contribuir com uma parcela significativa na economia do País com os nove milhões de hectares reflorestados, tanto pela maior participação no Produto Interno Bruto, quanto pela geração de 3,75 milhões de empregos em 2019 (IBÁ, 2020). O mercado de madeira em tora deverá ser suprido com maior participação das florestas plantadas, em decorrência das preocupações crescentes, no mercado internacional, quanto ao risco de extinção de espécies florestais nativas, como o mogno, cerejeira, jatobá-pequeno, entre outras (SNIF, 2020).

O mogno brasileiro (Swietenia macrophylla King.) pertence à família Meliaceae e pode ser encontrada nas florestas de terra firme da Amazônia brasileira. Devido ao seu alto valor econômico, o mogno sofreu intensas explorações, causando redução da variabilidade genética das populações remanescentes da Amazônia (FERNANDES, 2015), afetando a capacidade de regeneração da espécie, dizimando inúmeras árvores adultas e diminuindo a disponibilidade de sementes (LOPES et al., 2003).

O incentivo ao reflorestamento é uma das maneiras de evitar a extinção do mogno e o desaparecimento das reservas naturais desta espécie, mas os cultivos puros têm sido limitados devido aos ataques de larvas de broca-das-meliáceas (Hypsipyla grandella Zeller), que destroem a gema terminal das plantas jovens, acarretando a redução do vigor e a bifurcação do tronco (COUTO et al., 2004). A procura por alternativas para o cultivo dessa espécie com resistência a estresses 
bióticos tem sido um grande desafio para a comunidade científica.

Devido às dificuldades de propagação seminal de várias espécies nativas, como o mogno brasileiro, a propagação vegetativa torna-se uma alternativa de multiplicação para finalidades comercias. Com isso, as técnicas de cultura de tecidos permitem a manutenção de coleções vivas dos mais variados tipos de espécies vegetais de importância econômica ou em extinção. $\mathrm{Na}$ área florestal, esta se encontra embutida nos programas de pesquisa, onde tem sido utilizada na preservação de germoplasma, produção de plantas livres de doenças por meio de ápices caulinares e meristemas, multiplicação rápida de plantas selecionadas em períodos de tempo e espaço físico reduzidos, rejuvenescimento clonal e produção de mudas de clones selecionados (XAVIER et al., 2013), acelerando os programas de propagação clonal de genótipos de alto valor comercial e de difícil enraizamento.

Diante o exposto, o presente trabalho teve por objetivo determinar os aspectos físicos e verificar o efeito de diferentes concentrações e tempos de hipoclorito de sódio combinado com diferentes luminosidades na germinação in vitro das sementes, verificar o efeito de diferentes concentrações de 6-benzilaminopurina (BAP) e ácido naftalenoacético (ANA) na multiplicação in vitro dos brotos, a fim de fornecer informações sobre o desenvolvimento da espécie e sua posterior produção de mudas.

\section{MATERIAL E MÉTODOS}

\subsection{Biometria e germinação in vitro}

A coleta das sementes de mogno foi realizada, em quatro matrizes, de acordo com o potencial de vigor da população, nos municípios de Cáceres e Figueirópolis D’Oeste no Estado de Mato Grosso, em julho de 2017. Estas foram beneficiadas e armazenadas em câmara fria no Laboratório de Biotecnologia, Tecnologia e Produção de Sementes Florestais da Universidade Federal de Mato Grosso, campus de Cuiabá (MT).

Para a análise biométrica foi realizada a determinação do tamanho médio das sementes, com quatro repetições de 25 sementes, sendo mensuradas: largura, espessura e comprimento, em milímetros ( $\mathrm{mm}$ ), por meio de paquímetro digital.

Para a germinação in vitro, as sementes foram desinfestadas em câmara de fluxo laminar e imersas em álcool $70 \%$ por aproximadamente dois minutos, e logo em seguida imersas em hipoclorito de sódio a 2,5\% (v/v), com tempos de imersão variando de 0 a 40 minutos. Posteriormente, as sementes foram imersas em fungicida benlate com $2 \mathrm{~g} \mathrm{~L}^{-1} \mathrm{e}$, em seguida, passando pela tríplice lavagem em água destilada e autoclavada. O meio de cultura foi constituído de sais e vitaminas MS (Murashige; Skoog, 1962) adicionado de $30 \mathrm{~g}$ $\mathrm{L}^{-1}$ de sacarose e $0,01 \mathrm{~g} \mathrm{~L}^{-1}$ de mioinositol, com $\mathrm{pH}$ de $5,8 \pm$ 0,01 . Foram inoculadas quatro sementes por frasco no meio de cultura e mantidas em sala de crescimento com luz (irradiância de $30 \mu \mathrm{mol} \mathrm{m} \mathrm{m}^{-2} \mathrm{~s}^{-1}$ ) e no escuro, ambas na temperatura de $25 \pm 2^{\circ} \mathrm{C}$.

$\mathrm{O}$ delineamento foi o inteiramente casualizado em esquema fatorial $2 \times 5$, totalizando 10 tratamentos, cinco repetições e quatro sementes/repetição. Foram avaliados, semanalmente, durante o período de 30 dias, a porcentagem de germinação (\%GER), tempo médio de germinação (TM), porcentagem de contaminação por fungos (\%CONTF) e bactérias (\%CONTB) e o índice de velocidade de germinação (IVG), de acordo com Maguire (1962) (Equação 1):

$$
\mathrm{IVG}=\frac{\mathrm{N} 1}{\mathrm{D} 1}+\frac{N 2}{D 2}+\ldots+\frac{N n}{D n}
$$

em que: $\mathrm{N} 1=\mathrm{n}^{\circ}$ de sementes germinadas na $1^{\circ}$ contagem; $\mathrm{D} 1=\mathrm{n}^{\mathrm{o}}$ de dias para a $1^{\circ}$ contagem; $\mathrm{Nn}=\mathrm{n}^{\circ}$ de sementes germinadas na última contagem e $\mathrm{Dn}=\mathrm{n}^{\circ}$ de dias para a última contagem.

\subsection{Multiplicação in vitro}

Para a multiplicação in vitro foram instalados 2 experimentos, sendo denominados de "1" para o efeito de regulador de crescimento na indução de brotações, a partir de segmento apical, intermediário e basal de mogno, e " 2 " para o efeito de reguladores de crescimento e combinações na indução de brotações, a partir de brotações da multiplicação in vitro.

No experimento 1 os explantes foram excisados e inoculados, aleatoriamente, em tubos de ensaio contendo sais e vitaminas MS, acrescidos de $0,01 \mathrm{mg} \mathrm{L}^{-1}$ de mioinositol, 30 $\mathrm{g} \mathrm{L}^{-1}$ de sacarose, $5,5 \mathrm{~g}$ de ágar e de diferentes combinações de 6- benzilaminopirina-BAP $\left(0,0 ; 0,25 ; 0,50\right.$ e 1,00 $\left.\mathrm{mg} \mathrm{L}^{-1}\right)$. O delineamento utilizado foi o inteiramente casualizado em esquema fatorial $3 \times 4$, totalizando 12 tratamentos de cinco repetições e quatro explantes/repetição. Foram avaliados a porcentagem de brotação e o número médio de brotos por explantes (NMBE), semanalmente, durante 56 dias.

No experimento 2 foram utilizados explantes retirados do experimento 1 , isentos de contaminação. Os brotos de mogno foram excisados, em câmara de fluxo laminar e inoculados em meio de cultura de sais e vitaminas MS, acrescidos de $0,01 \mathrm{mg} \mathrm{L}^{-1}$ de mioinositol, $30 \mathrm{~g} \mathrm{~L}^{-1}$ de sacarose e 5,5 g de ágar, e variadas concentrações de 6benzilaminopirina-BAP $\left(0,0 ; 0,25 ; 1,0\right.$ e $\left.2,5 \mathrm{mg} \mathrm{L}^{-1}\right)$ e de ácido naftaleno acético- ANA $\left(0,0 ; 0,25 ; 1,0\right.$ e $\left.2,5 \mathrm{mg} \mathrm{L}^{-1}\right)$ e um tratamento adicional com combinação de 5,0 $\mathrm{mg} \mathrm{L}^{-1}$ de BAP e 5,0 $\mathrm{mg} \mathrm{L}^{-1}$ de ANA. Neste experimento o delineamento utilizado foi o inteiramente casualizado com 10 tratamentos, quatro repetições e três brotos/repetição. Foram avaliados semanalmente, durante o período de 30 dias, a porcentagem de brotação e porcentagem de calos.

Para todas as análises estatísticas foi empregado o programa estatístico R versão 3.3.3 (R CORE TEAM, 2017) e o pacote adicional Experimental Designs (Expdes) (FERREIRA et al., 2013).

\section{RESULTADOS}

\subsection{Biometria e germinação in vitro}

Os dados de biometria das sementes de mogno apresentaram valores médios de altura, largura e espessura de 24,19, 11,97 e 3,68 mm, respectivamente.

Para a germinação in vitro de mogno a análise de variância indicou que houve interação significativa entre os fatores: tempo de imersão em hipoclorito de sódio e luminosidade para as variáveis: índice de velocidade de germinação (IVG), tempo médio de germinação (TM), porcentagem de germinação (\%GER), porcentagem de contaminação por fungos (\%CONTF) e bactérias (\%CONTB). Dessa forma, cada fator foi avaliado de forma independente. Para o fator luminosidade, houve diferença significativa para os tempos de imersão em hipoclorito de sódio para as variáveis: índice de velocidade de germinação (IVG), tempo médio de germinação (TM) e porcentagem de contaminação por fungos $(\% \mathrm{CONTB})$.

A análise de regressão linear simples foi significativa $(p<0,05)$ para a variável IVG em relação ao tempo de imersão das sementes no hipoclorito de sódio, sendo o maior tempo 
de imersão observou-se o maior IVG. Dessa forma, o maior valor de IVG foi alcançado quando as sementes foram submersas no tempo de 40 minutos (Figura 1A). A análise de regressão linear múltipla foi significativa $(\mathrm{p}<0,05)$ para a variável TM em relação ao tempo de imersão das sementes no hipoclorito de sódio, sendo que o tempo médio de germinação que obteve o melhor resultado foi o de 10 minutos (Figura 1B).
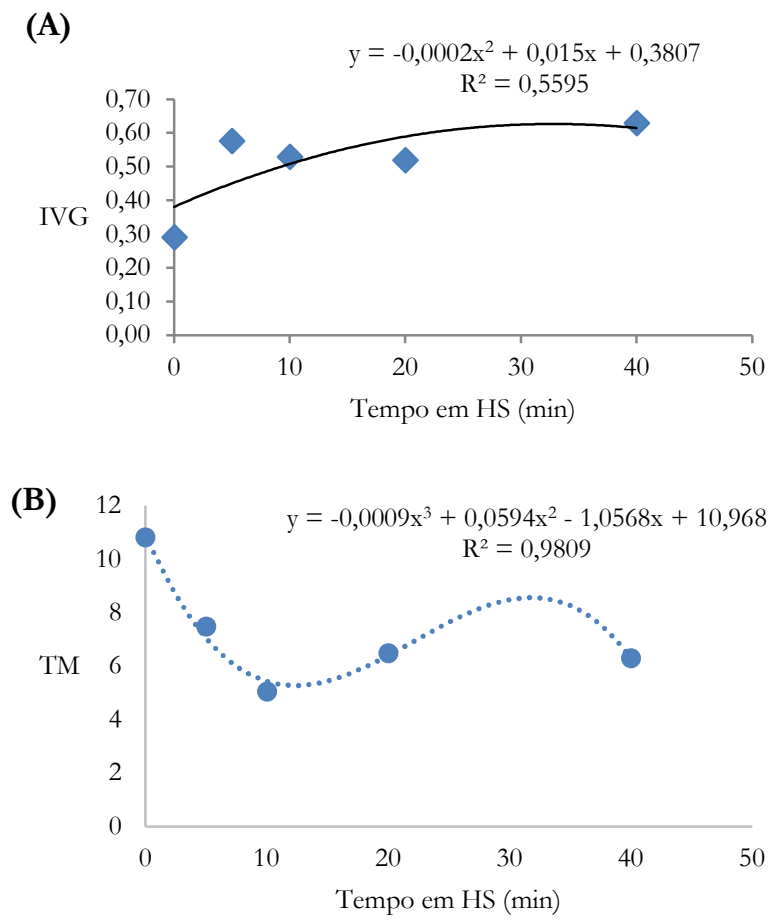

Figura 1. Índice de velocidade de germinação (A) e tempo médio de germinação (TM) de sementes de mogno brasileiro em função de tempo na imersão de hipoclorito de sódio.

Figure 1. Germination speed index (A) and mean germination time (TM) of Brazilian mahogany seeds as a function of time in the immersion of sodium hypochlorite.

Em relação à germinação de sementes, os fatores: luminosidade e tempo de imersão no hipoclorito de sódio, não influenciaram nas mesmas, podendo ser observada a germinação aos quatro dias de inoculação. Pode-se também observar que boa parte das sementes foi contaminada por fungos e bactérias e mesmo assim foram capazes de germinar não havendo prejuízos na fase inicial.

Em relação à luminosidade (Figura 2), a porcentagem de germinação do tratamento com zero minuto de imersão no hipoclorito em ambiente escuro foi superior ao tratamento com zero minuto de imersão no ambiente com luz, apesar de estatisticamente não apresentarem diferença estatística.

Em relação à contaminação por bactérias, o tempo de imersão em hipoclorito de sódio apresentou diferença significativa, e pela regressão linear múltipla mostra que quanto maior o tempo de imersão das sementes no hipoclorito de sódio, menor o percentual de contaminação das mesmas (Figura 3A). Para a contaminação por fungos, o hipoclorito de sódio não foi capaz de inibir a proliferação dos mesmos, dessa maneira, em todos os tratamentos houve a presença de fungos (Figura 3B). Observou-se ainda que o tempo em imersão no hipoclorito de sódio, com exceção do tempo de 40 minutos, provocou o aumento da contaminação por fungos nas sementes.

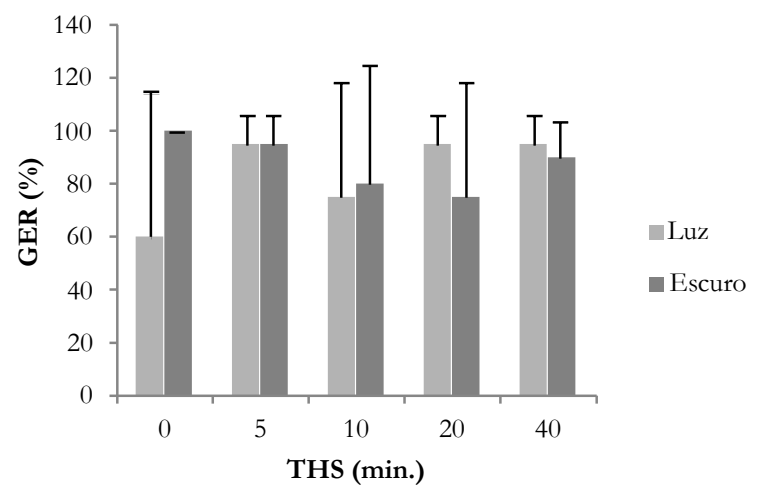

Figura 2. Porcentagem de germinação das sementes em função dos tratamentos.

Figure 2. Percentage of seed germination as a function of treatments.
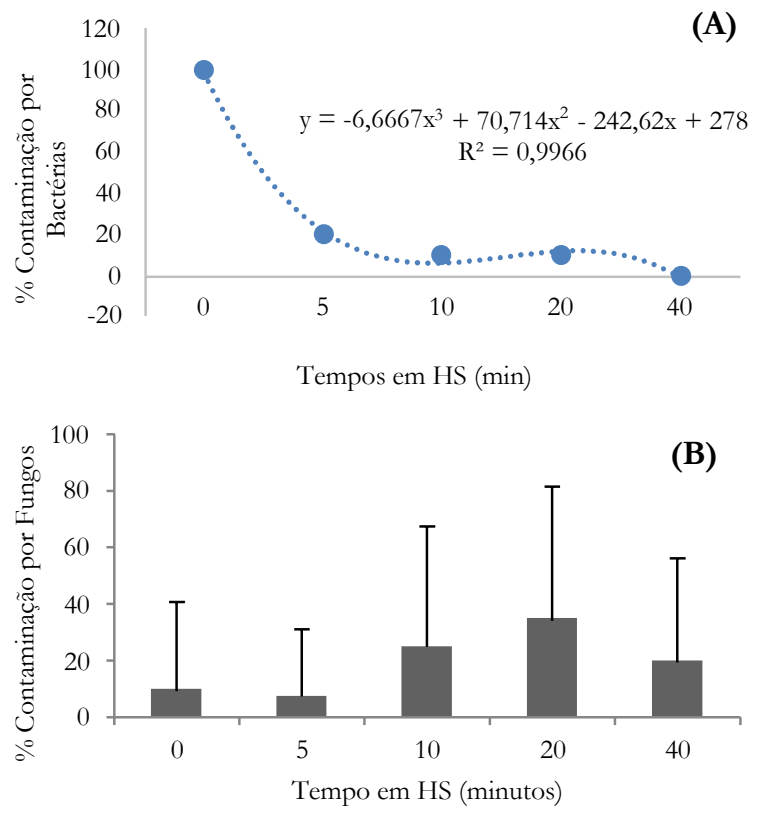

Figura 3. Porcentagem de contaminação por bactérias (A) e por fungos (B) em função do tempo de desinfestação. As barras indicam o desvio padrão.

Figure 3. Percentage of contamination by bacteria (A) and fungi (B) as a function of disinfestation time. The bars indicate the standard deviation.

\subsection{Multiplicação in vitro}

No experimento 1 pode-se observar que não houve interação entre os fatores porção da planta e concentração de $\mathrm{BAP}$, nas variáveis avaliadas: percentual de brotação, número total de brotos por explante e número médio de brotos por explante (NMBE). Dessa forma, cada fator foi avaliado de maneira independente.

Aos 14 dias foi observado que a porção intermediária da plântula foi a que obteve maior porcentagem de brotações, sendo superior a demais e a porção basal a que obteve a menor porcentagem (Figura 4A). Após 56 dias, os resultados obtidos se mantiveram (Figura 4B), sendo a porção intermediária ainda superior às demais e as concentrações de BAP não diferiram estatisticamente entre si.

No experimento 2 não houve interação entre concentração de BAP e concentração de ANA, para as 
variáveis porcentagem de brotação e porcentagem de calos. Dessa forma os fatores foram avaliados individualmente.

Aos 28 dias de implantação, as variáveis observadas não apresentavam diferenças significativas, contudo, pode-se observar na Figura 5 que os tratamentos T7 (0,0 BAP; 1,00 ANA) e T8 (0,0 BAP; 2,5 ANA), se destacaram por apresentar uma quantidade de calos superior aos demais tratamentos.
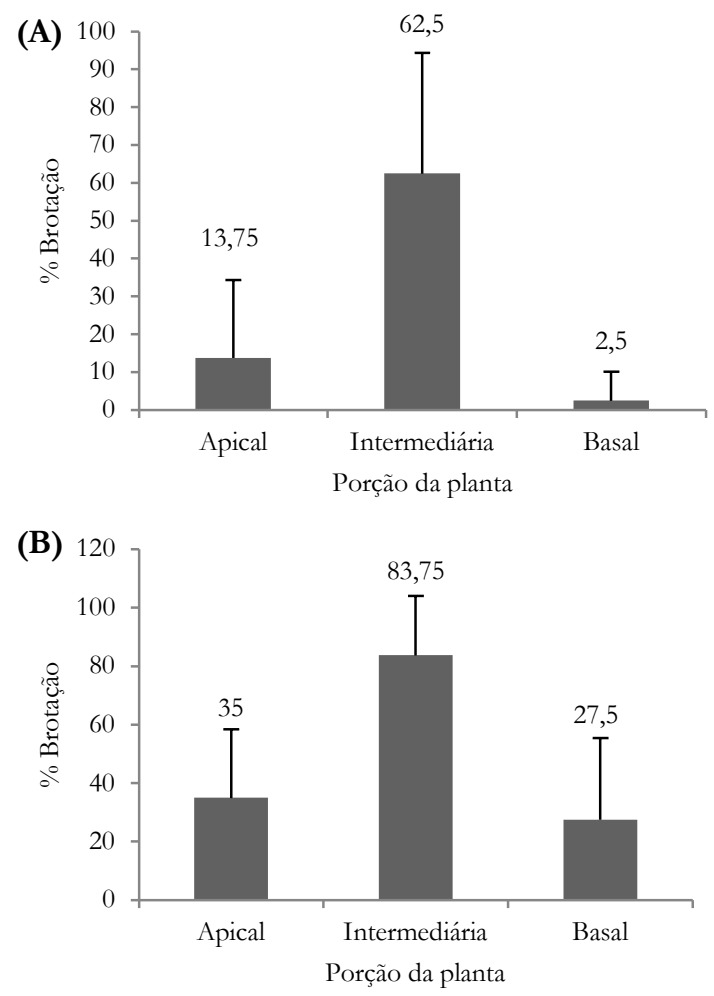

Figura 4. Porcentagem de brotações em função da porção da planta após 14(A) e 56(B) dias após implantação do experimento 1. Barras indicam o desvio padrão.

Figure 4. Percentage of shoots as a function of the part of the plant after $14(\mathrm{~A})$ and 56(B) days after implementation of experiment 1. Bars indicate the standard deviation.

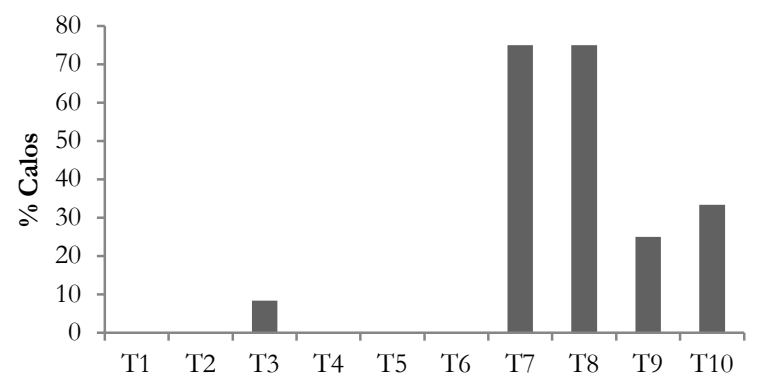

Figura 5. Porcentagem de calos em explantes de mogno em função dos tratamentos, aos 28 dias após a implantação do experimento 2. Figure 5. Percentage of callus in mahogany explants as a function of treatments, at 28 days after the implantation of experiment 2.

Quando analisada a variável percentual de calos, os tratamentos com 0,0 BAP e 1,0 ANA e com 0,0 BAP e 2,5 ANA foram superiores estatisticamente aos demais tratamentos. Pelos tratamentos com ANA foi possível concluir a maior porcentagem de brotação, em relação aos tratamentos com BAP, sendo estimulado pela função da ocorrência de gemas aleatórias e não a adição de reguladores de crescimento ao meio.

\section{DISCUSSÃO}

Os parâmetros encontrados neste trabalho para as sementes de mogno variaram em relação a trabalhos anteriores já publicados, sendo as médias de largura, altura e espessura das sementes aqui avaliadas um pouco menor do que as encontradas nos trabalhos de Moraes et al. (2013). Essas diferenças na altura, espessura e largura das sementes podem ser justificadas devido a diferença de região dos locais de coletas das matrizes, e as condições climáticas das mesmas. Segundo Santos et al. (2009), dentro de uma mesma espécie podem haver variações individuais devido às influências ambientais durante o desenvolvimento das sementes e à variabilidade genética das mesmas.

Em relação à germinação das sementes in vitro pode-se observar que boa parte das sementes foram contaminadas por fungos e bactérias e mesmo assim foram capazes de germinar não havendo prejuízos na fase inicial (Figura 1).

Em relação à luminosidade (Figura 2), pode-se inferir a presença de bactérias diazotróficas no tratamento do escuro que através da fixação biológica de oxigênio, promoveu o maior desenvolvimento das plantas, corroborando com Peng et al. (2002).

Para a contaminação por bactérias (Figura 3), o autor Fernandes (2015) estudando a mesma espécie, também encontrou o mesmo resultado para as sementes que não receberam a desinfestação com hipoclorito de sódio, no entanto Couto et al. (2004), encontraram índices inferiores de contaminação com maiores tempos de desinfestação das sementes no hipoclorito de sódio $2,5 \%$ aos 30 minutos.

O tempo em imersão no hipoclorito de sódio, com exceção do tempo de 40 minutos, provocou o aumento da contaminação por fungos nas sementes (Figura 3B). Uma hipótese para isso é que os fungos poderiam estar dentro das sementes e, por ocasião da imersão em hipoclorito de sódio, o tegumento das sementes amoleceu, desfazendo a barreira de saída e proliferação dos fungos no meio de cultura.

No experimento de multiplicação no experimento 1 avaliados aos 14 dias (Figura 4) foi observado que a porção intermediária da plântula obteve a maior porcentagem de brotações. Uma das justificativas para o maior número de brotações na porção intermediária da plântula é a maior quantidade de gemas axilares encontradas na mesma. Apesar das porções basal e apical não se diferirem estatisticamente, notou-se que a porção apical foi superior à porção basal. Ramos et al. (2014) realizando estudos sobre inhame (Dioscorea trifida) encontraram resultados superiores de brotações para a porção apical quando comparada com a porção basal da plântula.

Enquanto aos 56 dias, os resultados obtidos se mantiveram (Figura 4), sendo a porção intermediária ainda superior às demais. De acordo com Hartmann et al. (2010), essas diferenças entre as porções da planta ocorreram devido ao teor de carboidrato, assim como as quantidades de substâncias promotoras e inibidoras do enraizamento que variam ao longo do ramo.

No experimento 2 de multiplicação in vitro, aos 28 dias de cultivo (Figura 5) pode-se verificar que a variável percentual de calos, dos tratamentos com 0,0 BAP e 1,0 ANA e com 0,0 BAP e 2,5 ANA foram superiores aos demais tratamentos. Dessa forma, maiores concentrações de ANA apresentaram maiores quantidades de calos. Além disso, pode-se observar que auxina sintética ANA, influenciou significativamente na calogênese, pois quando esta encontrava ausente, não ocorreu formação de calos, com exceção do tratamento com 
1,0 BAP e 0,0 ANA. Deus et al (2007) estudando sobre calos em Eucalyptus grandis utilizando combinações de 2,4-D + ANA e TDZ + ANA, encontrou resultados semelhantes, onde os tratamentos que não continham ANA também não apresentou calos. A calogênese é um processo importante para a obtenção indireta de plantas. Os calos podem conter células ou grupos de células que possuem centros ativos de divisão celular. Em condições adequadas, esses centros são induzidos e se capacitam para produção de órgãos; em alguns casos nos quais já são capazes, os centros são apenas estimulados.

Pelos tratamentos com ANA foi possível concluir a maior porcentagem de brotação, em relação aos tratamentos com BAP, sendo estimulado pela função da ocorrência de gemas aleatórias. Corroborando com Brunetta et al. (2006), que observaram a porcentagem de brotação para os segmentos de epicótilos em função dos níveis de ANA, BAP e para as suas combinações, indicando que houve crescimento e desenvolvimento de brotações em gemas axilares préexistentes nos explantes.

\section{CONCLUSÕES}

Para a germinação in vitro a desinfestação das sementes deve ser realizada com imersão das sementes em hipoclorito de sódio $(2,5 \%)$ no tempo de 40 minutos.

O uso de explantes da porção intermediária é a que apresenta maior porcentagem de brotações de mogno brasileiro, independente da concentração de BAP. Bem como, as concentrações superiores de ANA apresentaram maiores percentuais de calos em explantes de mogno viabilizando a técnica para produção clonal.

\section{REFERENNCIAS}

BRUNETTA, J. M. F.C.; OTONI, W.C.; PINHEIRO, A.L.; FONSECA, E.P. Calogênese in vitro em segmentos de epicótilo de mogno (Swietenia macrophylla King) com o uso de 6-benzilaminopurina e ácido $\alpha$ - naftalenoacético. Scientia Forestalis, Piracicaba, n. 71, p. 19-24, 2006.

COUTO, J. M. F.; OTONI, W. C.; PINHEIRO, A. L.; FONSECA, E. P. Desinfestação e germinação in vitro de sementes de mogno (Swietenia macrophylla King). Revista Árvore, Viçosa, v. 28, n. 5, p. 633-642, 2004. Doi: https://doi.org/10.1590/S0100-67622004000500002.

DEUS, D. A.; ABREU, H. S.; PORTO, B. H. C.; DUARTE, M. S.; SOUZA, K. C. A. Análise da produção de calos em Eucalyptus grandis W. Hill ex. Maiden em diferentes concentrações de reguladores de crescimento. Ornamental Horticulture, Viçosa, v. 13, p. 85-87, 2007. DOI: https://doi.org/10.14295/oh.v13i0.1299

FERNANDES, C. A. Propagação vegetativa e estabelecimento in vitro de Swietenia macrophylla King e Handroanthus serratifolius (Vahl) S.O. Grose, 2015. 59p. [Dissertação Mestrado] - Instituto Nacional de Pesquisas da Amazônia, Manaus, 2015.

FERREIRA, E. B.; CAVALCANTI, P. P.; NOGUEIRA, D. A. ExpDes: experimental designs package. R package version 1.1.2. 2013. http://CRAN.R-project.org/ package $=$ ExpDes. Acessado em: 13 dez. 2017.
HARTMANN, H. T.; KESTER, D. E.; DAVIES, F. T.; GENEVE, R. L. Plant propagation: principles and practices. New Jersey: Prentice-Hall, 2010. 915p.

IBÁ_Indústria Brasileira de Árvores. Relatório 2020. https://iba.org/datafiles/publicacoes/relatorios/ibarelatorioanual2019.pdf. Acessado em: 13 out. 2020.

LOPES, S. C.; LAMEIRA, O. A.; FORTES, G. R. L. Comparação de procedimentos para descontaminação de explantes de mogno (Swietenia macrophylla King). Revista Ciências Agrárias, Belém, n. 40, p. 63-71, 2003.

MAGUIRRE, J. D. Speed of germination aid in selection and evaluation for seedling and vigour. Crop Science, Madison, v. 2, n. 2, p. 176-177, 1962. DOI: https://doi.org/10.2135/cropsci1962.0011183X000200 020033x.

MORAES, A. C. S.; FELIPE, S. H. S.; LEÃO, N. V. M.; SHIMIZU, E. S. C. Avaliação fisiológica de sementes de mogno brasileiro (Swietenia macrophylla King.) em diferentes temperaturas e substratos. In: Seminário de Iniciação Científica/Seminário de Pós-Graduação da Embrapa Amazônia Oriental, 17/1, Belém. 2013. Resumos... Disponível em: https://ainfo.cnptia.embrapa.br/digital/bitstream/item /91901/1/Resumo5.pdf. Acessado em: 12 nov. 2020.

MURASHIGE, T.; SKOOG, F. A revised medium for rapid growth and bioassays with tobacco tissue cultures. Physiologia Plantarum, Sweden, v. 15, p. 473-497, 1962.

PENG, S.; BISWAS, J. C.; LADHA, J. K. Influence of rhizobial inoculation on photosynthesis and grain yield of rice. Agronomy Journal, Dakota, v. 94, p. 925-929, 2002. DOI: https://doi.org/10.2134/agronj2002.9250.

RAMOS, A. S.; CASTRO, A. P.; MEDEIRO, C. M.; FRAXE, T. J. P.; MELO, S. R. C. Avaliação para obtenção de mudas de diferentes partes do tubérculo de cará roxo (Dioscorea trifida L. f.). Revista Brasileira de Agroecologia, Dois Vizinhos, v. 9, n. 1, p. 170-175, 2014.

R CORE TEAM. R: A language and environment for statistical computing. Vienna: $\mathrm{R}$ Foundation for Statistical Computing, 2017. Disponível em: http://www.R-project.org. Acessado em: 13 dez. 2017.

SANTOS, F. S.; PAULA, R. C.; SABONARO, D. Z.; VALADARES, J. Biometria e qualidade fisiológica de sementes de diferentes matrizes de Tabebuia chrysotricha (Mart. Ex A. DC.) Standl. Scientia Forestalis, Piracicaba, v. 37, p. 163-173, 2009.

SNIF_Sistema de Nacional de Informações Florestais. Recursos Florestais 2020. Disponível em: http://snif.florestal.gov.br/pt-br/especies-florestais. Acessado em: 02 nov. 2020.

XAVIER, A.; SANTOS, A. G.; WENDLING, I.; OLIVEIRA, L.M. Propagação vegetativa de cedro-rosa por miniestaquia. Revista Árvore, Viçosa, v. 27, n. 2, p. 193-143, 2003. DOI: http://dx.doi.org/10.1590/S010067622003000200003 